\title{
O ENSINO DE CIÊNCIAS NO ENSINO FUNDAMENTAL E MÉDIO: reflexões e perspectivas sobre a educação transformadora
}

\author{
Alexandre Fernando da Silva55 \\ José Heleno Ferreira 56 \\ Carlos Alexandre Viera ${ }^{57}$
}

\section{RESUMO}

O presente trabalho tem por objetivo discutir o ensino de ciências naturais nos anos iniciais do ensino fundamental e nível médio, sua importância na formação de cidadãos e no desenvolvimento social e econômico do país. Inicialmente descreve um breve histórico e as influências que permearam do ensino de ciências no Brasil e a construção de legislações que regem as bases curriculares atuais. A partir deste histórico apresenta o contexto atual através de estatísticas governamentais e estabelece comparativo entre o nível educacional brasileiro e os padrões internacionais de referência em ensino. Diante dos parâmetros descritos discute as causas dos níveis nacionais e alternativas didáticas para melhoria do ensino, aplicáveis no cotidiano da sala de aula. Dentre estas metodologias, destaca-se o ensino voltado a formação de cidadãos críticos e conscientes de sua condição de mundo através do ensino de ciências e como este caminho pode ser viável na construção de um país de indivíduos com saberes científicos e ativos perante os problemas da sociedade.

Palavras-chave: Ensino de Ciências. Educação Transformadora. Sociedade.

\footnotetext{
55 Mestre em Ciências (2016) e doutorando em Ciências pela Universidade de Franca, Bacharel e licenciado em Química pela Universidade do Estado de Minas Gerais - Unidade Divinópolis. E-mail: carlosalexvieira@yahoo.com.br.

56 Mestrado em Mídia e Conhecimento pela Universidade Federal de Santa Catarina (2001). Professor de Filosofia, Política Educacional e Metodologia Científica na Universidade do Estado de Minas Gerais - UEMG - Unidade Divinópolis. E-mail: zeheleno.ferreira@gmail.com.

57 Doutor em Ciências pela Universidade de Franca. Coordenador do curso de química e professor das disciplinas: química ambiental e química analítica na Universidade do Estado de Minas Gerais - Unidade de Divinópolis. E-mail: carlosalexvieira@yahoo.com.br.
} 


\title{
PERSPECTIVES ON TEACHING SCIENCE IN ELEMENTARY AND MIDDLE SCHOOL:
}

\author{
reflections on transformative education
}

\begin{abstract}
The present work aims at discussing the teaching of natural sciences in the initial years of elementary education and level, its importance in the formation of citizens and in the social and economic development of the country. It initially describes a brief history and influences that permeated the teaching of science in Brazil and the construction of the legislation governing the current curricula. From this history trajectory, it presents the current context through government statistics and establishes comparison with Brazilian educational levels and international standards of reference in education. Faced with the described parameters, it discusses the causes of the national levels and didactic alternatives for improvement of the teaching, applicable in the daily routine of the classroom. Among these methodologies, teaching is focused on the formation of critical citizens who are aware of their status in the world through science and in the way that this teaching can be viable in the construction of a country with individuals with scientific knowledge and that are active in the face of the problems of society.
\end{abstract}

Keywords: Science Education. Transformative Education. Society.

\section{PERSPECTIVAS SOBRE LA EDUCACIÓN CIENTÍFICA EN LA ENSEÑANZA PRIMARIA}

Y SECUNDARIA: reflexiones sobre la educación transformadora

\section{RESUMEN}

Este documento tiene como objetivo discutir la enseñanza de las ciencias naturales en los primeros años de la escuela primaria y el nivel, su importancia en la formación de los ciudadanos y el desarrollo social y económico del país. Inicialmente describe una breve historia y las influencias que impregnaron la enseñanza de la ciencia en Brasil y las leyes que rigen la construcción de las bases curriculares actuales. A partir de esta historia muestra el contexto actual a través de las estadísticas del gobierno y establece la comparación entre los niveles educativos de Brasil y las normas internacionales de referencia en la educación. Frente a los parámetros descritos se analizan las causas de los niveles nacionales y alternativas didácticas para mejorar la enseñanza, aplicable en el aula todos los días. Entre estos métodos, no hay educación dirigida a la formación de ciudadanos críticos y conscientes de su condición de mundo a través de la educación científica y la forma de esta manera puede ser factible construir un país de personas con conocimientos científicos y activos a los problemas de la sociedad.

Palabras clave: La Educación Científica. Educación Transformadora. La Sociedad. 


\section{INTRODUÇÃO}

O homem é parte da natureza e a busca pelo seu conhecimento é inerente à condição humana. Desde os primórdios, a humanidade busca compreender a natureza que a cerca, como forma de sobrevivência através da compreensão e domínio de fenômenos naturais. Talvez a ciência tenha surgido em paralelo com a espécie humana, mas percorreu um caminho até a formação de como a conhecemos hoje e ainda está em constante evolução. O mundo passou por inúmeras transformações desde os filósofos gregos, pautados, em diversos momentos, no empirismo, e o método científico trouxe a humanidade à sociedade tecnológica atual. Tais transformações tiveram como fruto mais recente a ciência moderna, com grande impulso no século XVII, focada na experimentação como forma de conhecer e delimitar leis naturais. Nascia a ciência moderna, apoiada em proeminentes mentes como as de Lavoisier e Galileu Galilei, que argumentavam que somente através de experimentos quantitativos poderíamos testar hipóteses e, seguramente, conhecer o mundo (PORTO, 2008).

A ciência é fruto do questionamento, é nele que se inicia o processo científico e para a figura do cientista perguntar é mais importante que responder. $O$ ato de questionar é inerente à condição humana, mas a ciência não sobrevive e nem dissemina suas descobertas sem que seja ensinada. O ensino de ciências é engrenagem fundamental na construção do método científico e, assim como as ciências, a forma de ensiná-las moldou-se através dos tempos.

Neste trabalho, o enfoque é o "ensino de ciências" que compreendese como a área definida pelo Exame Nacional do Ensino Médio - ENEM, como Ciências da Natureza e suas Tecnologias e as áreas de conhecimento específicas deste eixo: Química, Física e Biologia, considerando, paralelamente, a matemática e a leitura, conhecimentos fundamentais para a compreensão das ciências naturais. Dessa forma, após breve descrição do 
histórica, busca-se descrever o contexto atual do ensino de ciências em nosso país através de estatísticas governamentais e de órgãos internacionais, os desafios contemporâneos e perspectivas diante do cenário contemporâneo. Busca-se também discutir a importância do ensino científico na formação de cidadãos críticos, reflexivos e conscientes de sua condição de mundo e no desenvolvimento do país, tendo em vista que no mundo pós-moderno, em franco desenvolvimento tecnológico, a educação científica é ferramenta determinante na pujança econômica e social de países.

\section{BREVE HISTÓRICO DO ENSINO DE CIÊNCIAS NO BRASIL}

A escola é parte importante do contexto social e como tal reflete as mudanças da sociedade, assim há a necessidade de mudanças curriculares que atendam as novas perspectivas, de acordo com o atual momento histórico. A primeira fase do ensino no Brasil foi centrada no estudo de línguas clássicas e matemática, formatação herdada dos jesuítas que constituíram a organização do ensino no Brasil até então. A inserção de conteúdos científicos na educação ocorreu no início século XIX, como exigência das transformações que ocorriam naquele período em que a ciência crescia em descobertas e relevância (LUIZ, 2007). Neste período, há o surgimento de inúmeras descobertas e teorias científicas impactantes, como a Teoria da Evolução das Espécies, de Charles Darwin (1858), e a publicação do Traité élémentare de chimie (Tratado elementar de Química), de Lavoisier (1789), que ratificaram a importância das ciências na construção do mundo moderno e influenciaram no ensino formal em diversos países. Também neste período, o intenso desenvolvimento industrial concedeu nova conotação aos cientistas que se tornaram agentes do progresso tecnológico e econômico através de suas descobertas. Em paralelo, o ensino de ciências estava sob duas percepções, uma ciência para equacionar problemas cotidianos e a ciência acadêmica como precursora de novos cientistas. $O$ 
conhecimento acadêmico prevaleceu, apesar da primeira visão ecoar até os dias atuais.

Em se tratando da inserção no currículo escolar, a educação científica no Brasil tem início de fato na década de 1930, período marcado por um processo caracterizado como de inovação. O termo inovação é utilizado em educação como descritivo de melhoramento na qualidade do ensino, no entanto essa visão simplista designa algo acabado, o que de fato não ocorre na formação do conhecimento que deve ser constantemente aprimorado e adequado às necessidades impostas pela sociedade (GARCIA, 2009). Nesse contexto, o processo de aprimoramento do ensino de ciências no Brasil teve sequência na década de $1950 \mathrm{com}$ a produção de kits de experimentos, tradução de projetos norte americanos e a instituição de centros de estudo científico na década de 1960 (LUIZ, 2007). Após este período, houve a implementação de centros de pesquisa em ensino de ciências no Brasil, que atualmente são consolidados e se constituem como importantes fontes de conhecimento da área.

A legislação educacional brasileira acompanhou este processo, ainda que, muitas vezes, tardiamente. O Ministério da Educação e Cultura (MEC) estabelecia até o início da década de 1960 programa oficial para o ensino de ciências, que ocorria apenas nas duas últimas séries do ginásio com caráter meramente teórico e, no entanto, não estabelecia obrigatoriedade. Em 1961 é promulgada a Lei de Diretrizes e Bases da Educação Nacional (LDBEN $n^{\circ}$ 4024/61) que descentralizava as decisões curriculares sob responsabilidade do MEC e instituía a obrigatoriedade do ensino de ciências nas séries ginasiais (NASCIMENTO; FERNANDES; MENDONÇA, 2010). Mas apenas em 1971, através da Lei 5692/71, o ensino de ciências assume caráter oficial, com a obrigatoriedade em todas as $8^{a}$ séries do primeiro grau (BRASIL, 1971). Apesar das instituições legais deste período, o ensino de ciência transcorre de forma tecnicista, de modo a atender a demanda de industrialização, distanciando os estudantes do contato com o método científico. Compreender tais características do ensino de ciências pressupõe 
compreender também o contexto sociocultural e político do período, uma vez que o processo educacional, como todas as ações humanas, não é neutro e não pode ser compreendido de forma descontextualizada. O período em questão refere-se à ditadura civil-militar (1964-1985) e à ênfase, no que diz respeito às diretrizes governamentais, na modernização o país a curto prazo e no atendimento à demanda industrial e econômica, em detrimento da formação de indivíduos criticamente pensantes.

A década de 1980 foi um período de grandes transformações no país e no mundo. O Brasil foi marcado especialmente pela redemocratização, a partir de 1985, e o mundo pelo o declínio e fim da Guerra Fria. Tais fatos, ligados à busca pela paz mundial e à crescente preocupação com questões ambientais e direitos humanos, levaram à necessidade de formação de cidadãos preparados para o convívio social, bem como trouxeram à tona as discussões quanto à necessária superação da desigualdade social (NASCIMENTO; FERNANDES; MENDONÇA, 2010). Esses novos desafios da educação levaram à necessidade de mudanças na forma de ensinar ciências que deveria priorizar a formação cidadã e não somente técnica, que culminou com a promulgação, em 1996, da Lei de Diretrizes e Bases da Educação Nacional (LDB), Lei n 9.394. Em acordo com a nova LDB, em seu artigo 22 A, compreende-se que a "educação básica tem por finalidades desenvolver o educando, assegurar-lhe a formação comum indispensável para o exercício da cidadania e fornecer-lhe meios para progredir no trabalho e em estudos posteriores". (BRASIL, 1996) Tal visão inclui o saber científico que contribui para formação crítica de cidadãos sob a abordagem da atividade científica em torno do contexto histórico social e cultural (FERREIRA; OLIOSI, 2013). Baseado na LDB, foram publicados, em 1998, os Parâmetros Curriculares Nacionais para o Ensino Médio (PCNEM), produto de amplo debate acadêmico e social, e que delimitou competências básicas aos jovens que iniciam a vida adulta (BRASIL, 1997). Embora a publicação desses documentos seja considerada um avanço 
quanto ao ensino de ciências no Brasil, duas décadas depois os desafios persistem.

\section{O ENSINO DE CIÊNCIAS NO CONTEXTO ATUAL}

Nos últimos anos o Brasil passou por intensas mudanças econômicas e sociais que se refletem no modo como a sociedade vislumbra o país nos dias de hoje e no futuro. Mas, apesar do crescimento econômico e da ascensão social de grande parte da população, a educação universalizada e de qualidade persiste como um ponto crítico. Tal condição reflete diretamente no ensino científico. A realidade do ensino de ciências é preocupante para aqueles profissionais que atuam para a melhoria do ensino no Brasil, condição identificada por levantamentos realizados por órgãos de pesquisa que buscam identificar os níveis educacionais e problemas no ensino. Segundo o relatório Global Information Technology, divulgado em 2016 pelo Fórum Econômico Mundial, a qualidade da educação em matemática e ciências no Brasil tem níveis alarmantes em relação à apreensão de conceitos matemáticos e científicos, com o país ocupando a 133a posição dentre 139 países, ao lado de Moçambique e atrás de países como Zimbábue (54a) e Zâmbia (81a) e países vizinhos como Argentina (113a) e Uruguai (122a). Em relação ao sistema educacional geral, o Brasil ocupa a 131 a posição (UNESCO, 2016). Outro índice internacional de educação em que o Brasil aparece em condições precárias é o Programa Internacional de Avaliação de Alunos (PISA - sigla de Program for International Student Assessment), divulgado em 2016 pela OCDE - Organização para Cooperação e Desenvolvimento Econômico, em que aparece em 59a em

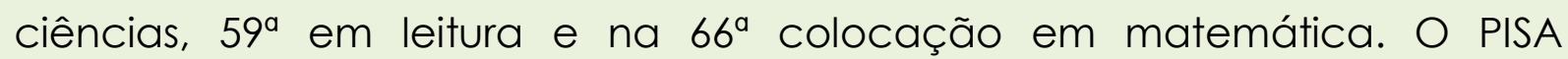
considera o resultado de prova coordenada pela OCDE e aplicada em 70 países trienalmente. Os resultados consideram sete níveis de proficiência ( $1 \mathrm{~b}$, 1a, 2, 3, 4, 5 e 6), sendo o nível 2 considerado básico. Nas três áreas, ciências, leitura e matemática, o país tem mais da metade dos estudantes abaixo do 
nível de proficiência - 56,6\%, 50,99\% e 70,25\%, respectivamente. Em cada exame, a OCDE delimita uma área como foco, em 2016 foi ciências. A avaliação consistiu de três competências científicas: explicar fenômenos e interpretar dados e evidências em acordo a conceitos científicos e ainda avaliar e planejar experimentos. No resultado, os estudantes brasileiros ficaram, na média, com 401 pontos, abaixo do índice médio da OCDE, que foi de 493 pontos (OCDE, 2016).

Elencar motivos e razões que conduzem os níveis educacionais brasileiros, especialmente o ensino de ciências, a patamares tão baixos, pode resultar numa análise superficial diante da variedade de condições e fatores que podem influenciar $O$ ensino e aprendizado e ainda $o$ desempenho em sistemas de avaliação. No entanto, alguns pontos podem ser claros indicativos dos resultados fracos. Aqui são elencados dois quesitos considerados fundamentais que atualmente estão em condições críticas: formação e valorização docente e acesso a laboratórios de ciências.

Contribui para que o entendimento de temas científicos se faça com maior profundidade $o$ fato de 0 ensino de ciências ser ministrado por professores com formação específica para tal, ou ainda que possuam alguma licenciatura. Segundo dados do Censo Escolar de 2016, do total dos professores que lecionam nos anos finais do ensino fundamental, $84,7 \%$ têm nível superior completo, sendo que, destes, apenas $78,6 \%$ são licenciados. Mas quando considera-se a formação específica para lecionar ciências, apenas $60 \%$ dos professores possuem formação adequada. No ensino médio os dados são semelhantes, sendo que $93,3 \%$ dos professores têm nível superior completo, mas apenas $82,9 \%$ destes possuem graduação em licenciatura. A formação específica varia dentre as disciplinas científicas. Em química, 60,6\% dos professores possuem formação adequada, em biologia este número melhora, com $79,4 \%$, mas em física o valor é de apenas $41,4 \%$ (INEP, 2017). Esses números são reflexo de uma realidade nacional, a desvalorização da profissão docente. O professor brasileiro é submetido a adversidades em seu cotidiano de atuação, como condições de trabalho 
deterioradas, longas jornadas, salas superlotadas e a constante cobrança de melhores desempenhos profissionais (SCHEIBE, 2010). Além destes fatores soma-se a indisciplina de estudantes e a situação de violência no entorno das unidades escolares, reflexo de condições sociais e econômicas adversas e excludentes que jovens de baixa renda enfrentam cotidianamente. Outro fator de relevância é a remuneração precária em comparativo com outros países da OCDE, considerando a carga horária de 40 horas semanais (CHALUS; CARISSIMI, 2011). A baixa remuneração e as más condições de trabalho fazem com que a licenciatura seja pouco atrativa para jovens estudantes que optam por outras carreiras e muitas vezes até ingressam na carreira docente, mas sem encará-la como uma profissão à qual possam se dedicar. Dessa forma, o magistério, muitas vezes, é visto apenas como uma ocupação temporária até que surja uma oportunidade mais rentável. Essa condição reflete no grande percentual de professores sem formação adequada, conforme apresentado nos números do último Censo Escolar.

Dentre os fatores importantes para a qualidade do ensino de ciências está a experimentação. A experimentação assistida e direcionada pode contribuir para a construção do conhecimento científico e, por isso, o acesso aos laboratórios de ciências é fundamental para que os estudantes assimilem o planejamento e a execução e possam discutir os experimentos científicos. O Brasil apresenta um déficit significativo neste quesito, segundo Censo Escolar de 2016 apenas $25,4 \%$ das escolas que oferecem anos finais do ensino fundamental possuem laboratórios de ciências. Em escolas de ensino médio, pouco mais da metade, cerca de $51,3 \%$, possuem laboratórios de ciências (INEP, 2017). Os números apresentados compreendem a totalidade das escolas do país, mas quando considera apenas escolas da rede pública, o número é retrato de uma condição ainda mais precária. Segundo o Observatório do Plano Nacional de Educação apenas 8,19\% das escolas da rede pública possuem laboratórios de ciências (TODOS PELA EDUCAÇÃO, 2017). 
A junção destes dois fatores, formação inadequada de docentes e precariedade na estrutura física, é indicativa das causas da baixa qualidade do ensino, mas não constitui a única causa. Há, para além destas duas questões, uma série de outros pontos relevantes que tornam o ensino um desafio à sociedade brasileira, como a universalização do acesso à escola, maiores investimentos políticos e pedagógicos nos cursos de licenciatura, formação continuada e valorização de professores em relação à remuneração e à equiparação com demais profissionais com formação universitária, estrutura física básica das escolas e, por fim, a própria desigualdade social que estabelece barreiras aos estudantes de baixa renda.

\section{ALTERNATIVAS AOS DESAFIOS DO ENSINO DE CIÊNCIAS}

Diante do cenário do ensino de ciências no Brasil não é difícil elencar os desafios para a educação científica. As carências estruturais e as condições de formação e atuação de professores são questões que demandam longo prazo, investimento público e social e políticas de Estado voltadas para resultados a longo prazo na melhoria do ensino de ciências e demais disciplinas. Neste sentido, a Academia Brasileira de Ciências apresentou em 2007 o documento "Ensino de ciências e educação básica: propostas para um sistema em " com proposta para o aprimoramento do ensino básico, especialmente o ensino de ciências. O documento foca em ações de longo prazo e que visam sanar os problemas citados no panorama descrito anteriormente no texto (HAMBURGER, E. W. et al, 2007). Após uma década, os problemas persistem! Além da efetiva cobrança que a sociedade pode (e deve) exercer sobre os gestores das instituições formais de educação, cabe aos agentes atuantes diretamente no ensino implementar soluções independentes e que possam ser feitas de imediato e com resultados práticos na aprendizagem. 
O ensino de ciências é desafiador aos educadores. Temas científicos geralmente tratam de partículas ínfimas invisiveis ao olho desarmado, mecanismos biológicos complexos que ocorrem no interior de células ou fenômenos físicos descritos através da matemática, que em geral demandam abstração, tanto para o educando como para o educador. Quando o professor de ciências não tem a formação específica na disciplina lecionada, o desafio torna-se maior, pois é preciso o domínio dos conceitos científicos para contornar a abstração e "levar" o aluno à apropriação do conhecimento. Neste sentido, a formação inicial do professor e sua atuação em disciplinas específicas tornam-se grandes desafios, mas não é possível desvinculá-las das condições de trabalho e da formação continuada, ou seja, da necessidade de aprimoramento e estudo contínuo durante a carreira (MARTINS, 2005).

A configuração da sala de aula tradicional é um dos grandes desafios ao educador científico quando se trata de tornar o ensino-aprendizagem de ciências significativo aos educandos, com apropriação de conceitos e conhecimentos úteis à vida cotidiana. Segundo Ausubel, o ensino expositivo não é de fato um problema, mas é preciso que as exposições sejam efetivas considerando a lógica da disciplina e a lógica dos alunos, para que o aprendizado de ciências além do significado lógico tenha significado psicológico para o educando (AUGUSTO; NETO, 2006). Neste sentido algumas condições podem ser utilizadas, como: estabelecer conexões entre variados pontos dos conteúdos, realizar estudos de casos a partir da proposição de problemas cotidianos, apresentar textos jornalísticos e propor a discussão entre os estudantes, explorar conhecimentos prévios dos educandos para que estes proponham problemas e discutam as alternativas de soluções. Um outro caminho é a exploração de textos científicos atuais e históricos, a discussão em sala através da argumentação entre o educador e educandos e entre os próprios educandos. A história influenciou nas descobertas e desenvolvimento da ciência. Explorar os contextos históricos no desenrolar do ensino de temas científicos é oportunidade para tornar o 
ensino significativo $e$ interessante aos olhos do estudante e abordar interdisciplinarmente temas no âmbito da filosofia e sociologia (MARINHO, 2008). O desenvolvimento tecnológico de determinada produção industrial pode revelar e propiciar o entendimento das fases do método cientifico, além de ser uma maneira de contextualizar o ensino. A partir destes pontos, instigar a construção de argumentos e, assim, propor um caminho para estimular a apropriação de conceitos, proposição de soluções e assimilação do significado dos conteúdos estudados (SASSERON; MARIA; CARVALHO, 2011).

O uso das palavras, exposições e argumentações pode ser complementado pela materialização dos conceitos científicos. Neste caminho, a experimentação é algo importante no ensino de ciências, especialmente considerando o método de produção de conhecimento científico: experimentar e elaborar hipóteses. A barreira está na ausência de laboratórios de ciências na maioria das escolas brasileiras, o que constitui na privação dos estudantes no uso da prática experimentativa, na ilustração dos fenômenos naturais estudados teoricamente. A experimentação em laboratórios de ciências é essencial, mas não isoladamente, todo o contexto social da sala de aula e demais ambientes escolares são importantes na formação científica dos educandos (SASSERON; MARIA; CARVALHO, 2011). Mesmo reconhecendo a ausência de laboratórios de ciências na maioria das escolas brasileiras, o que agrava as dificuldades quanto ao ensino de ciências, é possível propor alternativas viáveis para $\circ$ uso de experimentação. Na literatura há vários relatos sobre experimentação com materiais alternativos e montagem de kits com materiais de baixo custo e fácil acesso para uso em sala, sem a necessidade de laboratório (VIEIRA, C.A. et al., 2010). Outro caminho são oficinas para produção de materiais de uso cotidiano, como produtos de limpeza, também com uso de materiais e reagentes alternativos (VIEIRA; DA SILVA, 2016).

Perante os desafios estruturais das escolas brasileiras e a carência de recursos, a experimentação com materiais alternativos é um caminho para 
transpor essas barreiras e levar o educando à compreensão de conceitos científicos e a relação dos mesmos com a vida cotidiana.

\section{A EDUCAÇÃO TRANSFORMADORA PARA O ENSINO DE CIÊNCIAS}

Pensar o ensino de ciências pressupõe um questionamento: afinal, o que é ciência? Questão aparentemente simples, mas ao percebê-la em perspectiva mais próxima é possivel vê-la em sua complexidade. Apesar da ciência ser algo que permeia o mundo atual, não há definição delimitada. Essa ausência talvez seja pela amplitude do termo, mas existem três pontos que a justificam: primeiramente. a incompletude da definição, sempre há algo a excluir ou incluir; segundo, a complexidade inerente ao tema; e, terceiro ponto, a própria falta de acordo entre definições (FRANCELIN, 2004). Mas para além da definição, está o fato do que é ciência e como ela está presente no mundo contemporâneo, em todos os instantes da vida cotidiana. Partindo deste pressuposto, o ensino de ciências é uma forma de levar o estudante a interpretar 0 mundo que o cerca e através desta compreensão torná-lo indivíduo pensante e crítico. A formação científica, além de contribuir para a formação de cidadãos, está intrinsicamente ligada ao desenvolvimento social, político e econômico do país. Neste ponto, várias abordagens têm sido adotadas para o ensino de ciências em níveis fundamental e médio, mas algo fica claro: a importância da ciência e tecnologia na educação básica. Neste sentido, em encontro de especialistas de vários países, promovido pela UNESCO em 1983, sobre a inclusão das ciências e tecnologias no ensino básico, prevaleceu o entendimento quanto ao potencial do ensino de ciências no tocante à promoção do pensamento lógico sobre fatos cotidianos e solvência de problemas práticos por parte de crianças. Dessa forma, tal ensino pode - e deve - cumprir um importante papel relacionado à promoção do desenvolvimento intelectual em ciências e demais áreas do conhecimento e 
assim melhorar a qualidade de vida pelo exercício da cidadania (UNESCO, 1983).

Essa percepção sobre o ensino de ciências surge em paralelo à abordagem construtivista que ficou conhecida como Ciência, Tecnologia e Sociedade - CTS. O enfoque CTS no contexto educativo busca colocar a ciência e tecnologia vinculadas a questões sociológicas através de pontos como: questionar as formas tradicionais de estudo da natureza e a distinção convencional entre conhecimento teórico e prático e promover a democratização do conhecimento científico e tecnológico, a partir de discussões contextualizadas sobre avanços científicos e tecnológicos e as consequências sociais e os interesses políticos e econômicos (APARECIDA; PINHEIRO, 2007). A visão da UNESCO sobre o ensino de ciências e o enfoque CTS influíram na elaboração dos Parâmetros Curriculares Nacionais - PCN's. Este documento indica que a aprendizagem é produto do envolvimento do estudante com a construção do conhecimento a partir daquilo que ele já sabe a partir de suas vivências. Assim, o ensino de ciências precisa partir da problematização de temas relevantes ao aluno e que envolvam contextos históricos, sociais, econômicos e culturais (BRASIL, 1997). Neste contexto, a escolarização compartimentada, em conteúdos isolados, não tem mais espaço, mas, sim, a interconexão e interação no processo de ensino aprendizagem e assim contribuir para formação intelectual e cidadã de estudantes. Segundo ( FRACALANZA; AMARAL \& GOUVEIA; 1987):

... O ensino de ciências no primeiro grau, entre outros aspectos, deve contribuir para o domínio das técnicas de leitura e escrita; permitir o aprendizado dos conceitos básicos das ciências naturais e da aplicação dos princípios aprendidos a situações práticas; possibilitar a compreensão das relações entre a ciência e a sociedade e dos mecanismos de produção e apropriação dos conhecimentos científicos e tecnológicos; garantir a transmissão e a sistematização dos saberes e da cultura regional e local.

As ciências naturais são comumente divididas nos conteúdos tradicionais de física, química e biologia, o que pode aparentar uma separação e distanciamento entre os conhecimentos, o que na prática não 
ocorre. A ciência, nas suas variadas áreas de estudo, está interconectada, e o ensino científico deve considerar essas interconexões. A separação arbitrária em disciplinas pode levar ao ensino de conteúdos isolados, de forma sequencial, sem conexão e enciclopédico, o que Paulo Freire denominou de educação bancária. Essa forma de educação, na concepção freireana, está presente no ensino científico através de metodologia que valoriza a memorização em detrimento da problematização, assim o educando estará apto a memorizar símbolos, equações, sistemas e classificações, mas não conseguirá decodificá-los e nem mesmo usar tais informações para entendimento do mundo e de sua condição nele. Sob esta ótica, pode-se argumentar que a educação científica deve ser neutra, apolítica e distanciar-se da problematização. No entanto, dessa forma estará carregada de valores tecnológicos dominantes em que o objetivo é a formação em atendimento a interesses de mercado em detrimento dos interesses humanos. Aliado a essas questões, há ainda o fato de que a educação bancária apresenta se organiza a partir da lógica do repasse de informações e da suposta supremacia daquele que sabe lo professor) sobre aquele que não sabe (o aluno), o que limita a curiosidade inerente do educando, como denuncia Paulo Freire (FREIRE, 1987). Em oposição à educação bancária, Paulo Freire propõe uma educação dialógica, baseada em conceitos centrais de colaboração, organização, síntese cultural e organização (CROSARA; LEITE; FEITOSA, 2011). Essa perspectiva freireana recai sobre a atuação do educador, que em sua posição pode agir e distanciar-se dos métodos tradicionalistas de ensino enciclopédico e engajar em aulas que valorizam 0 diálogo e problematização sob o enfoque de temas científicos. A atuação docente não é neutra, assim como não o são todas as ações humanas, mesmo que inconscientemente, as ações educativas são permeadas por posturas ideológicas e políticas. Cabe ao educador se valer desta consciência e atuar como agentes libertadores através da decodificação, promoção e problematização do conhecimento científico. Neste contexto, Freire afirma: 
Os educadores progressistas precisam convencer-se de que não são puros ensinantes - isso não existe - puros especialistas da docência. Nós somos militantes políticos porque somos professores e professoras. Nossa tarefa não se esgota no ensino da matemática, da geografia, da sintaxe, da história. Implicando a seriedade e a competência com que ensinemos esses conteúdos, nossa tarefa exige o nosso compromisso e engajamento em favor da superação das injustiças sociais (FREIRE, 1997, p.54).

As ciências naturais muitas vezes são percebidas por alunos e até mesmo por professores como algo abstrato e distante da realidade, apesar de sabidamente fazerem parte da vida humana moderna. Nesta percepção, o processo de ensino aprendizagem prende-se às perspectivas tradicionalistas em que prevalece $\mathrm{o}$ ensino tecnicista com as ideias de neutralidade política e histórica da educação. No entanto, ao observar a própria história da ciência é evidente a influência da historicidade com todas as variáveis sociais e políticas nos contextos de descobertas científicas e avanços tecnológicos. A distância entre ciências e sociedades é inexistente, sendo que a própria ciência é produto histórico das interações e ações humanas. Trazendo este contexto para o ensino de ciências nos níveis iniciais e médio da formação escolar é possivel estabelecer paralelos entre os conteúdos a serem ministrados e as ocorrências sociais e políticas contemporâneas. Tais ideias vão ao encontro do trabalho de Teixeira (2003) que faz o diálogo entre a Pedagogia Histórico-Crítica (PHC) e o Movimento Ciência-Tecnologia-Sociedade-Ambiente (CTSA) discutindo a contribuição dessa relação no redirecionamento do ensino de ciências. Teixeira (2003) ressalta pontos convergentes entre essas duas ideias, como a prática social em que a inserção de temas vinculados ao contexto socioeconômico e realidade social são ponto de partida para o processo de ensino. Avalia ainda pontos convergentes entre as metodologias de ensino, conteúdos e formação de professores entre as duas correntes teóricas. Cita, ainda, os objetivos educacionais entre as duas correntes, afirmando que ambas percebem a escola como instrumento de formação para a cidadania, apesar de autores que trabalham com a CTS abordarem a ciência e seus 
impactos sociais de forma neutra e autores de PHC serem mais incisivos quanto à crítica social, no entanto não há contraponto e sim complemento entre os pontos de discussão (TEIXEIRA, 2003).

A perspectiva social não pode ser deixada de lado em um país tão desigual. Há que se considerar ainda que tal desigualdade reflete diretamente nas condições de ensino e nos resultados educacionais, como apresentado anteriormente no texto. Perspectiva esta que converge com as ideias de Paulo Freire, que vislumbra a educação como ferramenta libertadora de homens, não apenas multiplicadora. Assim, a temática social não pode ser abandonada, mesmo no ensino de ciências, conforme afirma Freire:

...é preciso que a educação esteja - em seu conteúdo, em seus programas e em seus métodos - adaptada ao fim que se persegue: permitir ao homem chegar a ser sujeito, construir-se como pessoa, transformar o mundo, estabelecer com os outros homens relações de reciprocidade, fazer a cultura e a história (FREIRE, 1979, p.21).

A educação precisa ter como eixo principal a formação de mentes pensantes criticamente, não apenas técnicas e cientificistas. O cientificismo exalta o método científico e a crença de que através deste e do conhecimento produzido haverá soluções para todos os problemas do mundo. Essa visão exerce função ideológica de dominação, especialmente arraigada no modo de produção capitalista, em que técnica e ciência são interdependentes e estão a serviço da dominação do homem sobre a natureza e do homem sobre o homem. Segundo Santos e Mortimer (2002), os fenômenos tecnológicos vão além da explicação puramente técnica sobre o funcionamento de determinados mecanismos e o preparo do indivíduo para manuseio de ferramentas. Estes conhecimentos são úteis, mas o ensino apenas tecnicista se enquadra na concepção alienante. Para estes autores mesmo que o ensino enfoque na visão CTS, é preciso contextualizar as implicações da ciência e tecnologia no comportamento da sociedade moderna (SANTOS; MORTIMER, 2002). 
A cultura humana e o desenrolar da história vão além da visão apenas racional da ciência e o entendimento de como o mundo é constituído na contemporaneidade e suas complexidades. Não é possível prescindir de uma visão crítica, especialmente sob a ótica social e das interações humanas. Tal visão pode estar presente mesmo quando atua sob o enfoque de CTS, visando uma formação ampla do educando e não apenas tecnicista. Neste sentido, o trabalho de Linsingem e Nascimento (2010) apresenta articulações entre este enfoque e as ideias de Paulo Freire e demonstra a clara possibilidade de formação ampla do educando para além de apenas técnica-científica, subsidiada pela filosofia educacional de Freire aplicada ao ensino de ciências (NASCIMENTO, 2006). Neste sentido, apontamentos são encontrados em artigos e estudos diversos, além dos Parâmetros Curriculares Nacionais (PCN's), documento que estabelece diretrizes ao ensino fundamental, ressaltam a importância do ensino transformador:

\begin{abstract}
... discussões acerca das relações entre Ciência, Tecnologia e Sociedade, no presente e no passado, no Brasil e no mundo, em vários contextos culturais. As questões éticas, valores e atitudes compreendidos nessas relações são aspectos fundamentais a investigar nos temas que se desenvolvem em sala de aula. A origem e o destino social dos recursos tecnológicos, as consequências para a saúde pessoal e ambiental e as vantagens sociais do emprego de determinadas tecnologias são exemplos de aspectos a serem investigados (BRASIL, 1997, p.41).
\end{abstract}

Ainda quanto aos PCN's, estes prescrevem como objetivo geral para o ensino fundamental, não apenas em ciências, a importância da formação cidadã:

Compreender a cidadania como participação social e política assim como exercício de direitos e deveres políticos, civis e sociais, adotando, no dia-a-dia, atitudes de solidariedade, cooperação, repúdio às injustiças, respeitando o outro e exigindo para si o mesmo respeito; posicionar-se de maneira crítica, responsável e construtiva nas diferentes situações sociais, utilizando o diálogo como forma de mediar conflitos e de tomar decisões coletivas (BRASIL, 1997, p.7).

Diante do exposto é preciso afirmar, que assim como o ensino de ciências deve ir além da transposição de conhecimentos sistematizados, o 
ato de lecionar numa perspectiva transformadora deve ser prática docente para além do que está nos PCN's. Mais que o cumprimento de uma obrigação curricular, mas motivada pela contribuição para a formação de pessoas que verão o mundo de forma crítica e proporá maneiras de aprimorá-lo no que tange ao indivíduo, bem como à sociedade.

\section{CONSIDERAÇÕES FINAIS}

Ao longo do texto, neste trabalho, buscou-se descrever e discutir o contexto histórico e atual do ensino de ciências na educação básica, desde os anos iniciais ao ensino médio. O eixo principal é a interação do ensino científico com questões cotidianas para a formação de cidadãos críticos, reflexivos e conscientes de sua condição no mundo e que utilizarão os saberes adquiridos durante o processo de escolarização em suas ações diárias.

A ciência não é uma ação isolada de grupos de pesquisadores enclausurados em laboratórios com equipamento avançados e manuseando substâncias com máscaras e luvas, a produção científica e avanços tecnológicos estão por toda a parte no mundo moderno, compondo o cotidiano. Não somente os resultados da ciência, mas o fazer ciência é cotidiano, devido a essa visão ressalta-se a importância do ensino de ciência transformador e formador de pensamento.

Os desafios do ensino de ciências são vários, incluindo questões básicas como estrutura física dos ambientes escolares e a formação e valorização de professores, mas diante de uma realidade complexa e que as soluções para tais questões devem ser fruto de políticas de Estado com resultados a longo prazo, portanto a atuação do professor torna-se fundamental. O desafio do docente é fazer o ensino de ciências com qualidade crítica, mesmo sem as condições necessárias e sob o uso dos recursos disponíveis. O próprio ato de abordar o conhecimento científico de forma contextualizada e instigadora, torna-se instrumento de transformação 
perante os educandos; pode valer-se de questionamentos, debates, contrapontos de ideias e utilizar tais oportunidades para o ensino para a cidadania, especialmente tolerância a ideias distintas e convivência em comunidade.

O ensino contextualizado e instigador pode ser precursor do interesse de estudantes sobre o conhecimento científico e tal interesse pode perdurar na maturidade e, assim, mais jovens seguirem a carreira científica. $O$ conhecimento científico e tecnológico é gerador de desenvolvimento econômico e social, ensinar ciências para a cidadania é um meio de transformar pessoas e nações.

\section{REFERÊNCIAS}

VIEIRA C.A. et al. Produção de "kits"com materiais alternativos para experimentação no Ensino Médio. Professores em Formação ISEC/ISED, n. 1, 2010.

APARECIDA, N.; PINHEIRO, M. Ciência, Tecnologia e Sociedade: a relevância do enfoque CTS para o contexto do Ensino Médio. Ciência e Educação, v. 13, p. 71-84, 2007.

AUGUSTO, J.; NETO, P. Teoria da aprendizagem significativa de David Ausubel: perguntas e respostas. Série-Estudos - Periódico do Mestrado em Educação da UCDB, p. 117-130, 2006.

BRASIL. LEI No 5.692, DE 11 DE AGOSTO DE 1971. Brasília: Presidência da República do Brasil, 1971. Disponível em: <http://www2.camara.leg.br/legin/fed/lei/1970-1979/lei-5692-11-agosto-1971357752-publicacaooriginal-1-pl.html> Acesso em: 10/03/2017

BRASIL. LEI No 9.394, DE 20 DE DEZEMBRO DE 1996. Brasília: Presidência da República do Brasil, 1971. Disponível em: < www.planalto.gov.br/ccivil_03/leis/L9394.htm> Acesso em: 10/03/2017

BRASIL, S. D. E. F. Parâmetros Curriculares Nacionais: Introdução aos Parâmetros Curriculares Nacionais1, 1997. Brasília. Disponível em: $<$ http://portal.mec.gov.br/seb/arquivos/pdf/livro01.pdf> Acesso em: $15 / 03 / 2017$

CHALUS, A.; CARISSIMI, V. A valorização do professor no Brasil no contexto das tendências globais. Jornal de Políticas Educacionais, p. 57-69, 2011.

HAMBURGER, E. W. et al Academia Brasileira de Ciências. O ensino de ciências e a educação básica: propostas para superar a crise. Rio de 
Janeiro.

Disponível

em:

$<$

http://www.schwartzman.org.br/simon/abcedcient.pdf > Acesso em: $17 / 03 / 2017$

LEITE.R.C.; FEITOSA, R.A. As contribuições de Paulo Freire para um Ensino de Ciências Dialógico. In: VIII ENPEC - Encontro Nacional de Pesquisa em Ensino de Ciências / I CIEC - Congreso lberoamericano de investigación em Ensenãnza de las Ciencias. Editora da ABRAPEC. Campinas, UNESP, 5 a 9 de dezembro de 2011.

TODOS PELA EDUCAÇÃO. Menos de $\mathbf{5 \%}$ das escolas tem infraestrutura adequada ao PNE. Disponível em: < http://www.todospelaeducacao.org.br/reportagens-tpe/30192/menos-de-5das-escolas-tem-infraestrutura-adequada-ao-pne/>. Acesso em: 20 março, 2017.

FERREIRA, A.; OLIOSI, E. C. A importância do ensino de ciências da natureza integrado a história da ciência e à filosofia da ciência: uma abordagem contextual. Revista da FAEEBA - Educação e Contemporaneidade, v. 22, p. 195-204, 2013.

FRANCELIN, M. M. Ciência, senso comum e revoluções científicas: ressonâncias e paradoxos. Ci. Inf. [online]. 2004, vol.33, n.3, pp.26-34..

FREIRE, P. Conscientização: teoria e prática da libertação - uma introdução ao pensamento de Paulo Freire. 4. ed. São Paulo: Cortez \& Moraes, 1979

FREIRE, P. Pedagogia do Oprimido. 17. ed. Rio de Janeiro, Paz e Terra, 1987.

FREIRE, P. Professora sim, tia não cartas a quem ousa ensinar. São Paulo, Olhos D'água, 1997.

GARCIA, P. S. Inovação e formação contínua de professores de ciências. Educação em foco, v. 13, p. 161-189, 2009.

FRACALANZA, H; AMARAL, I.A.; GOUVEIA, M. S. O ensino de ciências no primeiro grau. São Paulo: Atual, 1987. 124 p..

INEP. Censo Escolar da Educação Básica 2016 - Notas estatísticas, 2017. Disponível em: <http://download.inep.gov.br/educacao_basica/censo_escolar/notas_estati sticas/2017/notas_estatisticas_censo_escolar_da_educacao_basica_2016.pdf > Acesso em: 13/03/2017

LUIZ, W. Educação científica na perspectiva de letramento como prática social : funções, princípios e desafios. Revista Brasileira de Educação, v. 12, p. 474-550, 2007.

MARINHO, C. O Ensino de História da Química: Contrinuindo Para a Compreensão. Ciência e Educação, v. 14, p. 67-88, 2008.

MARTINS, A. F. P. Ensino de ciências: desafios à formação de professores. Revista Educação em Questão, v. 23, p. 53-65, 2005. 
NASCIMENTO, F. DO; FERNANDES, H. L.; MENDONÇA, V. M. DE. O ensino de ciências no Brasil: história, formação de professores e desafios atuais. Revista HISTEDBR On-line, p. 225-249, 2010.

NASCIMENTO, T. G. Articulações entre o enfoque CTS e a pedagogia de Paulo Freire como base para o ensino de ciências. Convergencia, v. 13, p. 95-116, 2006.

OECD (2016), Education at a Glance 2016: OECD Indicators, OECD Publishing, Paris. 2016.

PORTO, C. M. P. M. B. D. S. M. A evolução do pensamento cosmológico e o nascimento da ciência moderna. Revista Brasileira de Ensino de Física, v. 30 , n. 2008, p. 4601-4609, 2008.

SANTOS; , W. L. P. DOS; MORTIMER, E. F. Uma Análise de Pressupostos Teóricos da Abordagem C.T.S. (Ciência - Tecnologia - Sociedade) no Contexto da Educação Brasileira. Ensaio: Pesquisa em Educação em Ciências, v. 02, p. 123, 2002.

SASSERON, L. H.; MARIA, A.; CARVALHO, P. DE. Construindo Argumentação na Sala de Aula: A Presença do Ciclo Argumentativo, os Indicadores de Alfabetização Científica e o Padrão de Toulmin. Ciência e Educação, v. 17, p. 97-114, 2011.

SCHEIBE, L. Valorização e formação dos professores para a educação básica: questões desafiadoras para um novo plano nacional de educação. Educação e Sociedade., v. 31, p. 981-1000, 2010.

TEIXEIRA, P. M. M. A Educação Científica Sob a Perspectiva da Pedagogia Histórico-crítica e do Movimento C.T.S. no Ensino de Ciências. Ciência e Educação, v. 9, p. 177-190, 2003.

UNESCO. New trends in primary school science education. Vol 1. Paris, 1983

UNESCO. The Global Information Technology Report 2016 - Innovating in the Digital Economy. Genebra, 2016.

VIEIRA, C. A.; DA SILVA, A. F. Experimentação no Ensino de Química: Oficinas para Produção de Produtos de Limpeza e de Higiene Pessoal em Escolas da Rede Pública Estadual do Município de Divinópolis-MG e Região. Revista Brasileira de Educação e Cultura, p. 82-97, 2016.

Recebido em: Março de 2017. Aprovado em: Abril de 2017 